\title{
Aplicativo de Desenho do Google Drive: uma análise com foco na aprendizagem colaborativa com suporte computacional
}

\author{
Mixilene Sales Santos Lima ${ }^{1}$, Karla Angélica Silva do Nascimento ${ }^{1}$, Clodomir Silva \\ Lima Neto ${ }^{2}$, José Aires de Castro Filho ${ }^{3}$ \\ ${ }^{1}$ Universidade Federal do Ceará (UFC) \\ Caixa Postal 60020-110 - Fortaleza - CE - Brasil \\ ${ }^{2}$ Instituto Federal de Educação, Ciência e Tecnologia do Tocantins (IFTO) \\ Campus Araguatins - Tocantins - TO - Brasil \\ ${ }^{3}$ Instituto UFC Virtual - Universidade Federal do Ceará (UFC) \\ Caixa Postal 60440-554 - Fortaleza - CE - Brasil \\ \{mixilene, karla, aires\} Avirtual.ufc.br; clodomirnetodgmail.com
}

\begin{abstract}
This article shows how the Google Drive Design application can support collaborative learning during an activity with elementary school students in a public school cearense through the use of mobile devices while conducting an educational project. The methodology has a qualitative descriptive character which, among its possibilities of intervention, noted the actions and discussions of students and the application usage. The results highlight situations of interaction and collaboration of students enrolled in the application for the project, using an online environment as communication and production tool. Students perform information exchanges, favoring learning issues for creating educational materials.
\end{abstract}

\begin{abstract}
Resumo. Este artigo apresenta como o aplicativo de Desenho do Google Drive pode apoiar a aprendizagem colaborativa durante uma atividade com alunos do Ensino Fundamental de uma escola pública cearense por meio do uso de dispositivos móveis durante a realização de um projeto pedagógico. A metodologia tem uma abordagem qualitativa de caráter descritivo que, dentre suas possibilidades de intervenção, observou as ações e discussões dos alunos quanto ao uso de aplicativo. Os resultados destacam situações de interação e colaboração dos estudantes registrados no aplicativo durante o projeto, utilizando um ambiente online como ferramenta de comunicação e produção. Os alunos realizam trocas de informações, favorecendo a aprendizagem de assuntos para criação de materiais educativos.
\end{abstract}

\section{Introdução}

Atualmente, o avanço das tecnologias móveis favorece o surgimento de aplicações de software que possuem o mesmo propósito de mobilidade, conduzindo novas possibilidades à aprendizagem colaborativa (ZEMAN, 2011). Os dispositivos móveis, como smartphones, tablets ou netbooks, exemplificam forte capacidade de conectividade com a Internet e da disponibilidade de vários tipos e aplicativos móveis, promovendo a participação, compartilhamento e comunicação para tornar a colaboração à distância mais fácil (NASCIMENTO; CASTRO FILHO, 2015).

Diante disso, ainda há relativamente pouco entendimento acerca das formas como as tecnologias móveis podem ser projetadas e usadas para dar suporte às atividades colaborativas na escola. Nosso objetivo é apresentar como as funções colaborativas do aplicativo Desenho do Google Drive podem ser utilizadas no 
desenvolvimento de atividades pedagógicas por alunos do Ensino Fundamental. Neste trabalho, os aplicativos e dispositivos móveis são utilizados inclusive para se referir ao apoio que é dado à aprendizagem colaborativa, considerando a natureza interdependente e integral destes componentes.

A seguir faremos referência teórica sobre aprendizagem colaborativa com apoio computacional (Computer-Supported Collaborative Learning - CSCL) e suas características, situando a pesquisa. Apresentaremos também o público-alvo, como o aplicativo foi escolhido e os resultados analisados durante a realização das atividades deste estudo.

\section{Aprendizagem colaborativa com apoio computacional (CSCL)}

$\mathrm{Na}$ presente pesquisa, consideramos a ocorrência de aprendizagem colaborativa nas situações que evidenciam a participação dos alunos, por meio do trabalho em grupo ao aprender algo junto, enquanto utilizam aplicativo colaborativo com apoio de dispositivo móvel, especificamente o netbook. Assim, pontuamos interações ocorridas entre os estudantes durante a realização do projeto e relatos que evidenciam a colaboração, além de destacar as funcionalidades do recurso digital que ampliou essas interações.

A aprendizagem colaborativa com suporte computacional (CSCL) é fundamentada na teoria sociocultural de Vygotsky. Para Vygotsky (1984), a interação social é fundamental para a formação psicológica do indivíduo. O desenvolvimento das funções superiores ocorre a partir da internalização de sistemas simbólicos compartilhados por um determinado grupo social. A ideia de mediação está compreendida na relação entre o desenvolvimento humano e o processo sócio-histórico, ou seja, o conhecimento se efetiva pela mediação feita por outros sujeitos ou por meio de objetos do mundo que rodeia o indivíduo. É nessa mediação simbólica e na interação que o conhecimento se torna fruto de um processo sociocultural. A colaboração na teoria sociocultural enfatiza as interações entre alunos e a mediação de um adulto mais experiente.

O termo "com suporte computacional" veio agregar recursos digitais que propiciem e facilitem as interações entre pares. Segundo Lipponen (2002) existem duas interpretações da linha de pensamento de Vygotsky que balizam a CSCL: o aprender com o outro e o engajamento mútuo. A primeira está diretamente relacionada ao indivíduo que não sabe algo, mas aprende com o outro por meio da colaboração, assim: "as pessoas adquirem conhecimento e praticam novas competências, como resultados da internalização da aprendizagem colaborativa." Ou seja, "a colaboração é interpretada como facilitadora do desenvolvimento cognitivo individual" (Idem, p.03).

Para Stahl et al. (2006), a CSCL pressupõe o trabalho colaborativo entre estudantes, ao invés do uso de materiais de forma isolada. A aprendizagem acontece através da interação entre alunos, os quais levantam perguntas, realizam investigações e ensinam uns aos outros tanto de forma presencial quanto usando ambientes computacionais. Segundo os autores, algumas das vantagens disponibilizadas pela tecnologia para auxiliar a aprendizagem colaborativa são: a facilidade com que a tecnologia de informação e comunicação permite criar, mover, compartilhar informações na forma de textos, imagens e vídeos, e a capacidade de interagir e de produzir colaborativamente, fornecendo novas formas de aprendizagem. Segundo o 
autor, a interação entre alunos e professores desperta processos internos de desenvolvimento que levam os alunos a operarem em níveis mais avançados do que no trabalho individual. Tais processos são gradativamente internalizados, tornando-se parte essencial dos indivíduos.

Segundo Dillenbourg (2009), as tecnologias estão se tornando onipresente, a fronteira entre a colaboração apoiada por computador e outras formas de ação coletiva está desaparecendo. Para o autor, as atividades na perspectiva CSCL ocorrem dentro de ambientes de aprendizagem mais amplos que ocorrem em vários níveis sociais, em diferentes contextos e meios de comunicação. A aprendizagem colaborativa pode ser geralmente definida como atividades de aprendizagem expressamente concebidas e realizadas por pares ou em pequenos grupos interativos alocados em ambientes distintos. Do mesmo modo, promove a interação entre os alunos e favorece o compartilhamento de ideias e experiências entre eles. Por isso tem como foco a aprendizagem em grupo que envolve a colaboração numa relação horizontal e não linear.

Essa aprendizagem colaborativa difere consideravelmente da abordagem tradicional da Educação que enfatiza a mera transmissão de informações pelo professor e o trabalho individual dos alunos. O papel do professor numa visão de aprendizagem colaborativa muda de um simples provedor de conhecimento para um mediador, que discute juntamente com seus alunos.

Ambientes e aplicativos colaborativos auxiliam na resolução de tarefas proposta pelo professor de forma conjunta, "[...] a troca de conhecimentos e de experiências realça a aprendizagem e pode levar a um conhecimento mais duradouro" (TORRES; IRALA, 2014, p. 90). Neste sentido, o estudante, do mesmo modo que é responsável por sua aprendizagem, torna-se coautor da aprendizagem de seus colegas, o que implica o desenvolvimento de sua autonomia. Assim, enquanto os estudantes conduzem suas próprias ações, esses conferem trocas significativas com o outro, tanto no sentido de fornecer informações, soluções e descobertas quanto no sentido de colaborar com as ideias do outro.

Para ilustrar a CSCL no contexto do projeto realizado, destacamos situações que demonstram o uso das funcionalidades colaborativas do aplicativo colaborativo selecionado. Sendo que estas foram elencadas a partir da análise de dados, que ilustram evidências de aprendizagem, um processo construído a partir das interações com o meio e com os outros; assim, "é provocada por situações externas específicas, que podem ser desencadeadas por um educador no desenvolvimento das ações educativas, por outros sujeitos no processo de interação, entre outras" (SACCOL; SCHLEMMER; BARBOSA, 2011, p. 9).

A seguir destacamos a dinâmica da pesquisa, o público-alvo, como também o processo de seleção do aplicativo que foi utilizado durante a pesquisa e qual objetivo de cada função do aplicativo.

\section{Dinâmica da pesquisa}

A pesquisa tem abordagem qualitativa de caráter descritivo que, conforme Gil (2002), delineia as características de determinada população, fenômeno ou o estabelecimento de 
relações entre variáveis. Implica a utilização de questionário, entrevista e observação ordenada e padronizada.

Neste estudo, dentre suas possibilidades de intervenção, participaram 10 (dez) alunos do Ensino Fundamental de uma escola pública cearense, sendo observadas ações e discussões dos estudantes quanto ao uso de aplicativo e realizadas entrevistas, a fim de compreender o processo de aprendizagem colaborativa nas atividades de um projeto sobre sustentabilidade.

O projeto foi uma atividade de extensão da escola, uma vez que acontecia no contraturno das aulas dos alunos que, após apresentação do seu objetivo, decidiram participar. Assim, as atividades tiveram duração de 02 (dois) meses, sendo 12 (doze) encontros de três horas cada. A turma de alunos foi dividida em 03 (três) equipes, cuja ideia inicial foi produzir material pedagógico a partir de um aplicativo colaborativo online que sensibilizasse toda a comunidade escolar através de tirinhas relacionadas às ações sustentáveis para preservação da natureza. Para tanto, cada participante possuía um netbook para a realização das atividades.

A partir de conversas com a turma foram elencados subtemas para as discussões e produções semanais, tendo assuntos como: sustentabilidade, energia, reciclagem e água. Assim, a dinâmica do projeto contou com visualização de vídeo, pesquisa sobre o tema do dia, discussão do assunto e depois produção de tirinha no aplicativo. Ressaltamos ainda que todas essas atividades foram realizadas de modo colaborativo com o apoio do netbook.

Quanto à escolha do recurso, esta se deu após pesquisa de aplicativos que proporcionassem o trabalho colaborativo durante a produção de desenhos e/ou quadrinhos, dentre eles, selecionamos o Desenho do Google Drive. Este aplicativo se difere aos demais porque apresenta características favoráveis ao trabalho colaborativo: disponibiliza link para compartilhamento a todos que possuem uma conta de $e$-mail ou a qualquer outro recurso online (site, blog, redes sociais virtuais), possui versão em português, possibilita a inserção de imagens, formas geométricas, balões de diálogo e digitação de textos.

Além desses recursos, outras quatro funcionalidades fizeram a diferença durante o desenvolvimento das atividades entre grupos de alunos no projeto. A opção comentário possibilita notificar o arquivo compartilhado em uma comunicação assíncrona, disponibilizado também ao e-mail de todos os usuários. À medida que os comentários vão sendo respondidos, forma-se uma sequência de anotações parecida com um fórum de discussão que ficam gravados no arquivo. No entanto, a qualquer hora o usuário pode marcar como resolvido e imediatamente o comentário é excluído.

A ferramenta bate-papo possibilita a comunicação síncrona. Por meio da escrita os usuários podem conversar enquanto realizam o trabalho juntos. No geral disponibiliza o histórico das conversas. Porém, se a conversa for encerrada, esse recurso não permite acioná-la novamente, ou seja, o diálogo anterior não poderá ser visualizado. Assim, uma nova conversa é iniciada.

No item edição online todos os membros que compartilham o arquivo podem, em tempo real, editá-lo, seja digitando um texto, formatando, inserindo uma imagem ou link. Durante esta edição síncrona, as modificações são visíveis a todos, e cada ação do 
participante é identificada por uma cor. A edição assíncrona permite que, individualmente, o usuário edite sem acesso à Internet, mas ao se conectar, as alterações são atualizadas e os demais podem visualizar e dar continuidade ao trabalho.

O recurso histórico de revisões permite discriminar todas as alterações do arquivo, identificando quem fez o quê, o dia e a hora, como também possibilita recuperar a versão que quiser, ou seja, com as modificações de quem desejar, o que garante a manutenção de dados dos arquivos.

Todas as funcionalidades do Desenho do Google são favoráveis ao trabalho colaborativo. A seguir, destacamos os resultados da investigação a partir de como o trabalho colaborativo aconteceu com o uso do aplicativo selecionado.

\section{Resultados}

As discussões relacionadas aos resultados deste estudo serão entorno da descrição de como se deu o uso das funcionalidades do aplicativo pelos alunos durante a realização das atividades do projeto com apoio de netbooks. Além disso, discutirá uma situação de aprendizagem colaborativa de uma equipe e, consequentemente, uma visão geral de como era o trabalho colaborativo dos demais grupos ao utilizarem o aplicativo. As funcionalidades colaborativas facilitam a interação, o compartilhamento e a colaboração entre os usuários. Nesse caso, permitem que o trabalho realizado não seja de autoria de um, mas de todos os que contribuíram para a produção de algo em conjunto.

Na presente pesquisa, o aplicativo Desenho do Google foi utilizado para realizar o trabalho em grupo, porque possui funcionalidades que promovem e facilitam o trabalho colaborativo através da opção de compartilhamento, comentário, bate-papo, edição síncrona e assíncrona, salvar automático, histórico de revisões e visualização dos usuários conectados online. A pesquisadora criou e compartilhou um arquivo para a turma de alunos, como também por equipe. Os estudantes procuravam conhecer o recurso e realizar a atividade sobre o tema do encontro.

A opção de compartilhamento possibilitou o acesso de todos os membros das equipes e da pesquisadora nas produções, não limitando o número de pessoas. $\mathrm{O}$ arquivo foi criado com a possibilidade de adicionar mais pessoas e de limitar o tipo de acesso, seja somente para visualização, inserção de comentários ou edição de desenhos e textos. Os alunos puderam acessar de casa para fazer alterações, devido ao compartilhamento, todos receberam notificação por e-mail. Após dois ou três encontros, outros alunos ingressaram no projeto, mesmo assim foi possível compartilhar os arquivos já criados, o que permitiu que colaborassem na produção dos desenhos já iniciados.

Essa funcionalidade foi importante no trabalho colaborativo, visto que ampliou o acesso de outros membros das equipes que chegaram após ter sido criado o arquivo. Além de facilitar a distribuição das produções para outros integrantes da escola, como diretora e coordenadora, para que pudessem apreciar o que estava sendo feito no projeto. Além disso, possibilitou a ampla divulgação das atividades da turma.

Segundo Almeida e Valente (2011), as possibilidades oferecidas pelas tecnologias versam não somente do uso dos ambientes virtuais ou recursos digitais, mas repensa o fazer pedagógico situado em tempos, formas de relacionamento entre 
docentes e discentes e resultados distintos do que a escola costumava a trabalhar. Esses recursos estão em rede e permitem uma aproximação entre a realidade e a imaginação.

Com o apoio dos dispositivos móveis essas atividades puderam ser acessadas em diferentes ambientes, possibilitando o movimento, a interação entre pares. Desse modo, puderam interligar as situações vivenciadas nos espaços da escola, acessar e produzir informações de variados tipos como textos, áudios e imagens e compartilhar e debater sobre o tema sustentabilidade com outros alunos.

A funcionalidade comentário não foi utilizada durante a realização do projeto pelas equipes. Quando os alunos queriam deixar recado para os demais, eles usavam o próprio espaço de produção dos quadrinhos, ou seja, dentro do ambiente disponibilizado para o desenho ou para a criação do slide, como mostra a Figura 1.

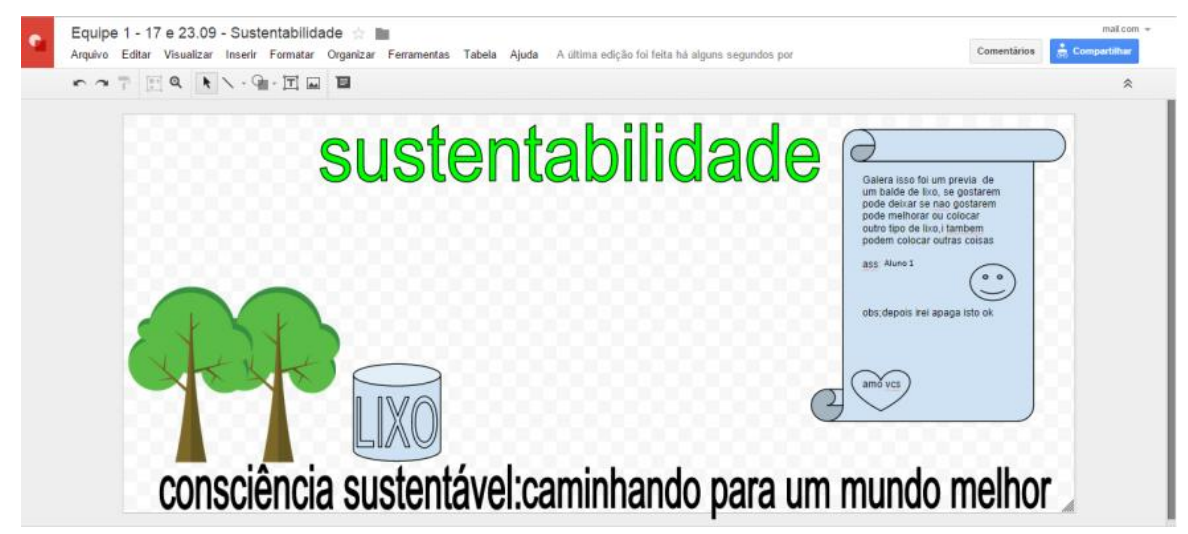

Figura 1 - Desenho utilizado como espaço de comentário

No desenho da Figura 1, o Aluno 1 fez um pergaminho com o seguinte recado para sua equipe: "Galera isso foi um previa de um balde de lixo, se gostarem pode deixar se não gostarem pode melhorar ou colocar outro tipo de lixo, e também podem colocar outras coisas. Ass: Aluno 1. Obs: depois irei apaga isto ok". Observamos que ele comenta que fez um modelo do cesto de lixo e que está aberto a sugestões. No final, assina e deixa claro que ainda não é o produto final.

A opção edição síncrona e assíncrona permitiu que a colaboração em si fosse possível entre os membros das equipes e que fosse editada ao mesmo tempo, de forma síncrona, visualizado o que cada um estava fazendo: modificando, excluindo, inserindo imagens, texto e acrescentando outros desenhos (Figura 1). Já a comunicação assíncrona aconteceu quando o Aluno 1, em horário e local diferentes da escola, fez modificações no desenho, adicionando e sugerindo alterações na produção da sua equipe.

Podemos perceber que essa funcionalidade promove o confronto de entendimentos, pois os alunos puderam colaborar de forma assíncrona, ou seja, contribuir na produção em um momento individual. Em seguida, os demais membros puderam decidir sobre como dar continuidade às ideias sugeridas. Para Nascimento e Castro Filho (2015) as tecnologias conectadas a Internet possibilitam o acesso a vários conteúdos e permitem interações em qualquer hora e lugar, transformando as noções de tempo e espaço de comunicação, ensino e aprendizagem.

O bate-papo garantiu a interação síncrona entre os alunos durante as atividades presenciais e nos momentos à distância. Esse foi uma das primeiras ferramentas que a 
turma descobriu logo depois que a pesquisadora mostrou e indicou quem era quem no aplicativo, pois cada aluno estava representado por uma cor e que todos estavam colaborando com o desenho. O Aluno 1 e o Aluno 4 inseriam carinhas, escrevendo "oi", "eww", utilizando abreviaturas das palavras (e.g. "vc", "pq", "tb"). Neste sentido, a pesquisadora explicou que o interessante seria discutir alguma atividade no espaço de trabalho. A partir desse comentário, o Aluno 1 escreveu: “o que é sustentabilidade?”. A pesquisadora entrou no bate-papo e encorajou a turma a responder, obtendo respostas como: "economizando energia" e "usando menos saco plástico".

Este recurso foi utilizado em outros momentos para facilitar a discussão, a negociação de ideias e tomadas de decisões da equipe. Por exemplo, o Aluno 8 iniciou uma conversa ao perguntar e indicar aos demais qual assunto abordariam no desenho. Escreveu ele: "ei galera vamos fazer sobre o consumo consciente??". Os demais concordaram, mas apresentam outras ideias, tal como: pesquisar vídeos sobre o assunto. As interações síncronas virtuais aconteciam, embora os estudantes estivessem no mesmo ambiente físico, utilizando um dispositivo.

O bate-papo propiciou a interação dos membros em tempo real, facilitando assim o desenvolvimento das produções, de modo a não interferir na atividade das outras equipes. Quando questionada durante a entrevista, a Aluna 9 deixa claro que: "[...] a gente usou muito o bate-papo do próprio recurso pra falar com os outros membros da equipe porque nem sempre a gente senta todo mundo junto, todo mundo perto". Essa funcionalidade permitiu que as equipes se posicionassem como quisessem. Apesar de estarem no mesmo ambiente, mas longe uns dos outros, sabiam que podiam permanecer em colaboração. Como afirma Saccol; Schlemmer; Barbosa (2011), embora não tenha sido criado para fins educacionais, com boas práticas pedagógicas os recursos que proporcionam comunicação síncrona pode ser uma estratégia significante para a aprendizagem colaborativa.

A opção histórico de revisões possibilitou rever e retornar às últimas edições, visto que os alunos, ocasionalmente, apagavam sem intenção todo o desenho. Isto possibilitou recuperar a versão anterior. Além do mais, esse recurso visualizou a atividade realizada por cada participante do grupo, pois cada ação ficou registrada pelo nome do aluno conectado, além de mostrar o horário das modificações (Figura 3). Percebemos que tal recurso proporciona o fazer e refazer das ações sem a preocupação de descaracterizar o trabalho final. Essa opção também serviu como instrumento de avaliação da pesquisadora que visualizou quem realmente colaborou nas atividades, incentivando a produção colaborativa.

A opção de visualização dos usuários conectados foi importante, porque permitiu a identificação de cada aluno. Isso facilitou a criação dos desenhos de forma síncrona, evitando que os estudantes interrompessem os demais, por exemplo, impediu que um desenho ficasse sobreposto a outro. Além do mais, serviu para identificar quem estava online para solicitar conversa no bate-papo.

Essas funcionalidades corroboraram para a elaboração de artefatos pedagógicos, a partir da interação e da colaboração entre os usuários. Segundo Machado (2009, p. 9) os aplicativos do Google são "ferramentas de ensino que permitem a aprendizagem colaborativa e a constante troca de ideias, sendo cada indivíduo responsável pelo resultado do grupo, ao assumir tarefas interdependentes" e acrescenta que as 
possibilidades de colaboração incentivam o conhecimento de todos que estão envolvidos, tanto pelos alunos quanto pelo professor.

Os alunos na entrevista, quando questionados sobre a experiência de usar um aplicativo colaborativo, deixaram claro que as atividades foram melhor desenvolvidas devido a possibilidade de trabalho em conjunto. A equipe 3 apresentou uma de suas produções, embora em uma apresentação curta, mas no momento expuseram o que foi feito de forma colaborativa, por exemplo, enquanto um explicava a tirinha e o que significava cada quadro, os outros fizeram a leitura dos textos escritos no desenho.

$\mathrm{Na}$ explicação do desenho, os alunos expressaram seu entendimento do conteúdo, bem como a relação com vídeos que haviam assistido. Demonstram que fizeram uma reflexão durante a produção do desenho para chegar ao produto final.

Citamos como caso análogo, o texto da Equipe 3 que, através da poesia, representou o desenho realizado. Com base na Figura 2, no primeiro texto, os alunos destacam a beleza e a pureza existentes no ambiente, No segundo, relatam as impurezas. Finalmente, no terceiro, deixam claro que toda beleza e pureza já não existem mais, devido a falta de consciência dos próprios indivíduos.

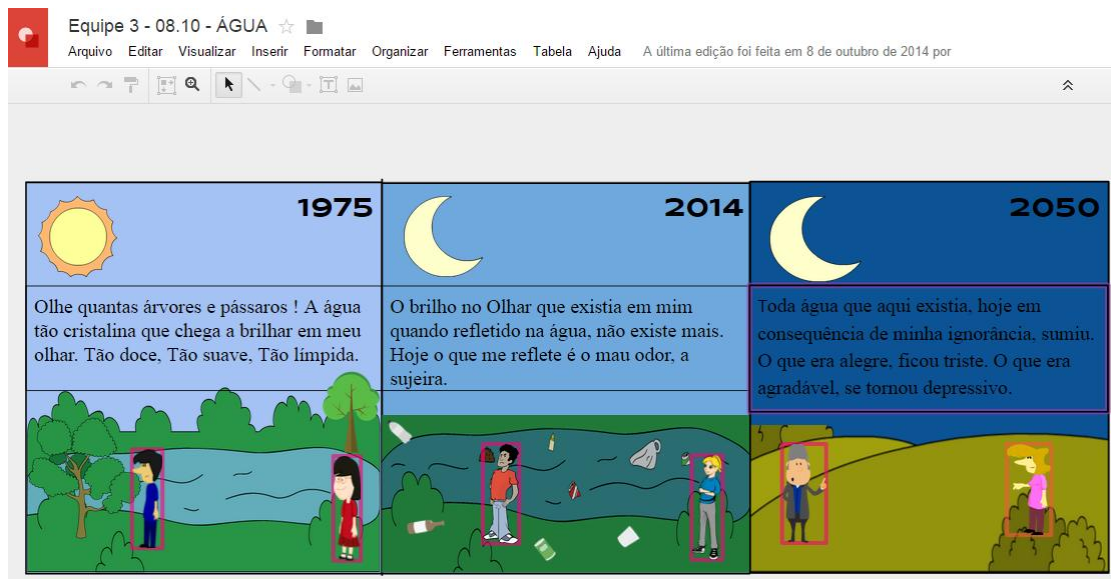

Figura 2 - Desenho de tema água - Equipe 3

Analisando o desenho, percebemos que tiveram o cuidado de representar três situações distintas. Destacaram na tirinha uma linha do tempo e a preocupação com as consequências da poluição no ambiente. No primeiro quadro, no ano de 1975, retratam um ambiente bonito com árvores e o rio limpo. No segundo, em 2014, retratam o mesmo lugar sujo, pouco arborizado e o rio poluído, para eles, uma situação que vivenciamos hoje. No ano de 2050 , terceiro quadro, os alunos imaginaram um aumento no desmatamento e a ausência do rio.

A produção da tirinha aconteceu não somente por meio de conversas presenciais, mas também de forma virtual. Isso ficou registrado no aplicativo, tanto pela produção dos desenhos, quanto pelo diálogo registrados nos recursos de bate-papo e do histórico de revisões, conforme representado na Figura 3, em que cada cor representa um aluno: a cor laranja se destina ao Aluno 8, a roxa ao Aluno 7 e a azul ao Aluno 9.

Dessa maneira, foi possível saber quem fazia o quê e em que horas, pois tudo ficou registrado no histórico de revisões. A Figura 3 destaca por cores os alunos em colaboração, ou seja, o momento da produção colaborativa. Percebemos que as 
V Congresso Brasileiro de Informática na Educação (CBIE 2016)

Anais do XXII Workshop de Informática na Escola (WIE 2016)

atividades promoveram momentos em que todos os componentes da equipe estavam em colaboração.

As atividades desenvolvidas pelos alunos indicaram que as informações recebidas por eles foram resignificadas e transformadas em conhecimento. Por meio dos desenhos, os alunos tiveram o cuidado e a sensibilidade de elaborar uma tirinha, representando a realidade ou pelo menos a visão de mundo dos alunos do que pode vir a acontecer se o meio ambiente não for preservado.

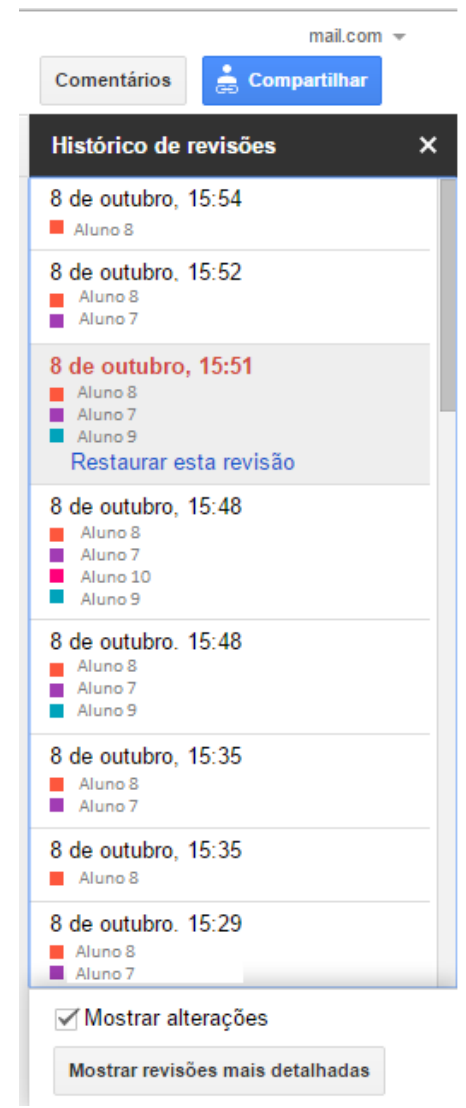

Figura 3 - Histórico de revisões

O aplicativo Desenho do Google Drive apoiou o desenvolvimento do trabalho colaborativo que contribuiu com o desenvolvimento de artefatos pedagógicos além da sala de aula. Ele foi utilizado como ferramenta essencial à aprendizagem (NORRIS e SOLOWAY, 2013) de maneira expressiva para os alunos em todas as atividades realizadas.

\section{Considerações finais}

O advento das tecnologias móveis e a sua imersão no cenário educacional refletem em mudanças positivas nas metodologias de ensino. Estes dispositivos e o uso de aplicativos que favoreçam a colaboração possibilitam a construção de uma aprendizagem colaborativa, bem como um compartilhamento recíproco de informações e conteúdos consolidados em sala de aula.

O referido estudo revela algumas estratégias de como usar o aplicativo Desenho do Google com alunos do Ensino Fundamental, possibilitando o desenvolvimento de 
V Congresso Brasileiro de Informática na Educação (CBIE 2016)

Anais do XXII Workshop de Informática na Escola (WIE 2016)

concepções relacionadas ao trabalho colaborativo em espaços diferentes de aprendizagem. O aplicativo oportunizou uma forma diferenciada dos alunos interagirem, ampliando os momentos de construção do conhecimento. Convém ressaltar que a diversidade de ferramentas deste aplicativo fornece aos alunos a execução colaborativa de inúmeras atividades, manifestando habilidades de interações sociais também no ambiente virtual.

Neste sentido, podemos inferir que o suporte pedagógico do aplicativo Desenho do Google Drive nas referidas atividades desta pesquisa, mostrou-se vantajoso ao trabalho colaborativo, propiciando a formação de indivíduos conscientes da necessidade de pensar em ações sustentáveis.

\section{Referências}

Almeida, M. E. B. de; Valente, J. A. Tecnologias e currículo: trajetórias convergentes ou divergentes. São Paulo: Paulus, p. 6-8, 2011.

Dillenbourg, P.; Järvelä, S.; Fischer, F. The evolution of research on computersupported collaborative learning. In:Technology-enhanced learning. Springer Netherlands, p. 3-19, 2009.

Gil, A. C. Como elaborar projetos de pesquisa. 4. ed. São Paulo: Atlas.

Lipponen, L. Exploring Foundations for Computer Supported Collaborative Learning. Department of Psychology, University of Helsinki, Finland. Proceedings of CSCL 2002, page 72-81.

Machado, A. C. T. Google Docs e Spreadsheets: Autoria colaborativa na web 2.0. Revista Científica do Departamento de Tecnologia do Centro Universitário de Belo Horizonte, UNI-BH, Volume 2, número 1, jan. 2009.

Nascimento, Karla A. S.; Castro Filho, José Aires. Aprendizagem móvel e suas tecnologias: uma revisão sistemática da literatura. In: Anais dos Workshops do Congresso Brasileiro de Informática na Educação. Congresso Brasileiro de Informática na Educação - CBIE, 2015. p. 721.

Norris, C.; Soloway, E. Substantive Educational Change is in the Palm of our Children's Hands. Handbook of mobile learning, 2013.

Saccol, A.; Schlemmer, E.; Barbosa, J. M-learning e ulearning: novas perspectivas da aprendizagem móvel e ubíqua. São Paulo: Pearson Prentice Hall, 2011.

Stahl, G.; Koschmann, T.; Suthers, D. Computer-supported collaborative learning: An historical perspective. Cambridge handbook of the learning sciences, v. 2006, p. 409426, 2006.

Torres, P. L.; Irala, E. A. F. Aprendizagem colaborativa: teoria e prática. In: Complexidade: redes e conexões na produção do conhecimento. Curitiba: Senar, p. 61-93, 2014.

Vygotsky, L.S. A Formação Social da Mente. São Paulo: Martins Fontes, 1984.

Zeman, E. What's driving Apple's 10 billion app success. Information Week, 2011. 